NASA-CR-204187

\title{
The unique significance and origin of the Cretaceous-Tertiary boundary: Historical context and burdens of proof
}

\author{
Graham Ryder \\ Lunar and Planetary Institute, 3600 Bay Area Boulevard. Houston, Texas 77058-1113
}

\begin{abstract}
The abruptness and intensity of the Cretaceous-Tertiary boundary have been deemphasized by some authors over recent years, mainly by those skeptical of an impact origin for the boundary. However, it was recognized at the birth of stratigraphy as both abrupt and of major importance. It was used to define the change from the Mesozoic to the Cenozoic; the boundary has become continually more precisely defined and its global sequences more correlatable. It is now unique in being an event boundary marked by an iridium-bearing layer of global extent, rather than an arbitrary boundary in a sequence of little change. The Permian-Triassic boundary, in contrast, is arbitrary and the transition is not yet proven to be abrupt, the extinctions that define it perhaps having taken place in pulses over several millions of years. Some of those who have denied the importance (and in some cases even the existence) of an impact in the Cretaceous-Tertiary extinctions have placed burdens of proof on the impact hypothesis that they do not place on strictly terrestrial mechanisms. Terrestrial mechanisms have always been unsatisfactory (or at least unconvincing for global, massive, multienvironment faunal change) and are now even more so. Some authors have required of the impact hypothesis attributes that are not inherent in it, including particular patterns of extinction selectivity and timing.
\end{abstract}

\section{INTRODUCTION}

Considerable scientific and public interest has attended the debate over the last 15 years about the nature and causes of the faunal transition from the Cretaceous Period to the Paleogene Period, more conmonly known as the Cretaceous-Tertiary boundary. The debate is noteworthy for its multidisciplinary participation, which has led to great advances as well as some difficulties and confusions. Immediately prior to the impact hypothesis of Alvarez et al. (1980), the boundary was generally' accepted as an extremely sharp one (e.g.. Bramlette, 1965; Alvarez et al.. 1980: Russell, 1979). Some authors, particularly (but certainly not restricted to) some paleontologists from both invertebrate and vertebrate disciplines, have recently deemphasized the abruptness of the transition and its importance, particularly in relation to other mass extinctions but also in absolute terms. This has been in parallel with attempts to deny any particular significance to any impact in the transition, whatever the reality or characteristics of an impact. In part this denial reflects the continuing influence of uniformitarianism in its erroneous guise of requiring slow, gradual change as well as the multiple meanings of "uniformitarianism" conflated by Lyell (1830, 1832. 1833) that facilitate unwitting circular arguments. One of those meanings of Lyell's was aniform rates of change.

This chapter, an amplification of Ryder (1994), has two main goals. The first is to briefly review the historical context and recognition of the Cretaceous-Tertiary boundary and to claim that the boundary truly represents the most clear example of a rapid mass extinction event. The boundary is historically recognized as critical or major and has become more precisely defineable with time since its original recognition. Its correlation with an iridium (Ir)-depositing or Ir-concentrating event is now undoubted. and the Ir is an important component of the definition of the boundary stratotype at El Kef. Tunisia. The

Ryder. G. 1990. The unique significance and origin of the Crelaceous-Tertiary boundary: Historical context and burdens of preof, in Ryder, G., Fastowsty D. and Gatrner. S. ed. The Cretaceus-Tentar: Event and Other Catastrophes in Earth History: Boulder. Colorado, Geological Society of America Special Patper 307 
boundary is unique in being an essentially nonarbitrary event boundary. Other mass extinction transitions, including the endPermian, may ultimately prove to be precisely definable and nonarbitrary, but at present they are not.

The second goal is to indicate that some opponents of the impact-generated mechanisms for extinction have required of it burdens of proof that they do not require of their own nonimpact mechanisms. This even applies to some workers who agree that the Ir-bearing layer was a consequence of an impact. They require of the impact hypothesis attributes that are not inherent in it: that is, they have set up inappropriate straw men in their attempts at counterrevolution. For instance. it has been common to claim that all extinctions are instantaneous following an impact (e.g.. Hallam, 1989). A few workers continue to deny that an impact occurred. attributing 6 igneous processes effects that have not been observed in action, have not been deduced from the geological record, and are not inherently plausible. However. this extreme position will be almost ignored in this chapter.

\section{RECOGNITION AND HISTORICAL DEFINITION OF THE K/T AND OTHER BOUNDARIES}

Disregarding the historical context of the concept of a Cretaceous-Tertiary boundary, some authors have recently deemphasized or questioned both the abruptness of the transition and its importance. It has been claimed that interest in the boundary reflects comparatively unimportant characteristics such as our childlike interest in the extinction of dinosaurs, our anthropocentric view that is biased in favor of the rise of mammals, the controversy (and hence journalistically favored polarization) stemming from the impact hypothesis. and the mere closeness of the boundary to the present. Thus Stunley (1987) in his review states that.. . these factors have led us to overrate the terminal Cretaceous crisis." Erwin (1993) listed six "really important events in the history of life on Earth" but added that he included the Cretaceous-Tertiary events only to forestall a "lot of caterwauling from a few mammals." Even Stephen Jay Gould (in Raup. 1991). who not only accepts but advocates the impact as the trigger of extinctions and accepts the particular significance of the extinctions. nonetheless suggested that it is "particulirly dear to our hearts because it wiped out the dinosaurs and gave mammals a chance." Even though insiders realize that some such statements may have been made tonglie-in-cheek, the statements diffuse and confuse the significance of the boundary and therefore the significance of studying it.

The Cretaceous-Tertiary houndary has been recognized as both major in importance and abruptness since the early decades of the nineteenth century, well before dinosaurs or iridium became geologically useful concepts. It was the first major boundary recognized. That it is most critically the Mesozoic-Cenozoic boundary is somewhat obscured by its more popular name of Cretaceous-Tertiary. Notwithstanding the unclear detinitions that attend what is meant by a mass extinction. I contend that the
Cretaceous-Tertiary boundary extinctions represent the most rapid or catastrophic and widespread example of a mass extinction. In comparison, the massive Permian-Triassic extinctions apparently took place over a period of several millions of years and cannot, at least yet, even be postulated as a (single) event.

\section{The importance of the boundary and the faunal change}

The recognition of a major and abrupt change that is the Cretaceous-Tertiary boundary took place (under catastrophic thinking. admittedly) at about 1810 at the very beginning of fossil-based stratigraphy. Cuvier had previously established the fact of extinction. The studies in the Paris Basin by Cuvier and Brongniart $(1811)$ detined the sharp transition. They found no transition between the chalk and the overlying "plastic clay." which had distinctive fossils. They recognized that there was probahly a separation in time between the two. based on depositional. not paleontological. evidence. In 1813, d'Halloy distinguished "cretaceous" from "mastozootic" (= Tertiary) as the upper two of four stratigraphic divisions of rocks, although precise limits at a type locality were not indicated (published as d'Halloy, 1822). The name "mastozootic" demonstrates that the faunal change was as important as the lithological change in making the distinctions. No Permian-Triassic boundary was then recognized; it was subsumed in the second group from the (now) upper Paleozoic through Jurassic (yet d'Halloy was more than familiar with the rocks that Murchison later included in the Permian). The recognition of a sharp boundary corresponding with the modern Cretaceous-Tertiary boundary preceded the concepts of mass extinctions (in a modern sense), dinosaurs, micropaleontology, iridium, thin sections, isotopes, and radioactivity and preceded the theory of natural selection. The term "Dinosiur" was invented by Richard Owen in 1841 with the recognition of nine genera at that time.

Phillips $(1841.1860)$ recognized major and significant divisions of stratigraphy, labeling them as Paleozoic, Mesozoic. and Cenozoic. He adopted the name Paleozoic from Adam Sedgwick. who had coined it to combine his Cambrian with Roderick Murchison's Silurian. Phillips followed d'Halloy's distinction of Permian rocks from Triassic rocks (around 1830) and recognized the critical significance of the MesozoicCenozolic change, at the Cretaceous-Tertiary boundary. This corresponded exactly with d Halloys division. Murchison's Permian (Murchivon er al.. 1845) originally included rocks now recognised as Triassic. so the Permian-Triassic boundary in the rocks of Europe was not obvious to everyone at around 18.40 Apparently d'Halloy's description in 1834 was closer to our modern definition of Permian than was Murchison's (Erwin. 1993). Under the then recently established uniformitarian principles (in all their conflated forms). passages or transitions were expected. Boundaries were insented for convenience of systematic arrangement and in consequence were expected to be arbitrarily assigned. This was (and remains) the case for the Permian-Triassic houndary. 
The expected passage beds for the Mesozoic-Cenozoic boundary were never found. That they did not appear seems to have been an embarrassment for Lyell and perhaps even more so later for Darwin. Lyell had subdivided the Cenozoic on the basis of molluscs yet noted that the faunal change from uppermost Cretaceous to lowermost (then) Eocene was equivalent to the entire Tertiary faunal change (Lyell, 1833, Chapter 23). Lyell accepted, on the authority of Deshayes, that the marked discordance extended "to all other departments of the animal kingdom, and to fossil plants." Although the relevant strata in Britain are indeed missing (though at worst only a few million years worth, not sixty), Lyell was familiar with European strata, where more complete successions occur. Even in England a near-complete succession occurs in Dorset. Lyell thought that the "missing" sequences (which under his uniformitarian concepts corresponded with missing time) might be found somewhere--that the hiatus resulted from shifting basins of deposition. Although Darwin was also familiar with this faunal change, his only mention of it concerns the abrupt extinction of the ammonites. Darwin $\$$ (1859. Chapter 11) explanation for the "wonderfully sudden" extinction of the ammonites, and other groups. is the "probable wide interval of time between our consecutive formations."

These original distinctions of the Mesozoic from the Cenozoic were founded in macrofossil sequences and included the presence of belemnites, ammonites, and rudists in the Cretaceous, quite distinct from the marine macrofauna of the overlying Tertiary. It was recognized that mammals were fairly common in Tertiary rocks (hence "mastozoic") but rare to absent in Mesozoic ones, and with the recognition of the Dinosauria it was realized that these animals dominated the large Mesozoic faunas but were completely absent from the Cenozoic. Such distinctions applied to the uppermost Cretaceous (the Maastrichtian stage. defined in 1849 by Dumont) and the lowermost Tertiary (the Danian stage defined in 1847 by Desor). Although the latter stage was originally assigned to the Mesozoic, further work showed that the Danian did not correlate with Cretaceous elsewhere. As paleontology and biostratigraphy progressed, it became clear that the distinctions shown by the macrofaunas were paralleled by distinctions in the microfaunas, and these microfaunas were better able to show that the distinction of Cretaceous from Tertiary was both abrupt and global in extent. Microfossils provide a much better statistical database from which to make conclusions than do macrofossils.

A review of the perspective just prior to the interjection of the Ir data into the debate shows that many and varied paleontologists were cognizant of the reality of the importance of the boundary. Colbert (1965) took pains to show that the "age of reptiles" was not the same as the Mesozoic; the reptiles he described included those of the Permian. $\mathrm{He}$ referred to the extinctions at the end of the Cretaceous as The Grealt Extinction. While noting that there were others, he claimed that none of these had the finality of the several parallel extinctions that marked the end of the Mesozoic world. Bramlette (196.5) claimed that the extinction of some large populations thriving towards the end of Mesozoic time was more demonstrably abrupt than that at the end of the Paleozoic. He emphasized invertebrate extinction, whereas Colbert (1965) emphasized vertebrate extinction. The invertebrates were most obviously and strikingly represented by marine planktonic forms and those forms dependent on plankton, such as ammonites and belemnites.

Nonetheless, the recognition of an abrupt faunal break in the record does not automatically lead to the recognition of an abrupt faunal break in reality. The immense faunal break, even where it occurs without significant lithological change, has been used to infer the presence of a sedimentological and time break even with no other supporting evidence. For example, for northeast Mexico sections, Hay (1960) claimed that the faunal change from the Mendez. Formation (Maastrichtian) to the Vasquez Formation (Danian) spoke unequivocably for a hiatus of some extent. even though there is "little field evidence for an erosional break." The withdrawal of the sea, erosion, and subsequent rise of the sea is couched in uniformitarian terms, and arguments that the Mendez is more indurated than the Vasquez. that its microfossils are more recrystallized, and that there is an apparent weathering zone at the top of the Mendez do not seem to be borne out by more modern studies. Instead, these arguments are a clear demonstration of the power of theory to induce particular observations, in this case according to thenaccepted philosophies of uniformitarianism that included (rightly or wrongly) the concept of slow, gradual change. A similar argument was made by Rainwater (1960) for the Cretaceous-Tertiary rocks in the Gulf Coastal Plain: "An important unconformity separates the two, as evidenced by a great change in faunas." He concluded that this probably represented considerable time.

Overall. it is safe to infer that even prior to the impact hypothesis of Alvarez et al. (1980), many paleontologists and biostratigraphers recognized that the Cretaceous-Tertiary boundary was both an abrupt and important transition. They nevertheless had a strong propensity to impose upon the boundary some cause that was mundane, noncatastrophic, and uniformitarian (in the then-accepted meaning) (e.g. Newell, 1962. 1963).

\section{The precision and correlation of the Cretaceous-Tertiary and other boundaries}

There appears to have been little difficulty in pinning down the Cretaceous-Tertiary boundary in most marine sequences since the mid-1800)s. Most specialists concur that the boundary can be identified with relative ease and precision in local sections (Russell. 1979). Nonmarine sequences have been a greater problem. A question as to whether the Danian in its type area should be included with the Creticeous was resolved negatively when the Danian was shown to correspond with a facies of rocks already defined as post-Cretaceous. Inclusion of the Danian within the Mesozoic appears to have been more influ- 
enced by its chalk facies at the type localities than by its fauna; both microfaunas and macrofaunas of the Danian show affinities with Tertiary life-forms. Although there were claims based on molluscan affinities for including the Danian within the Mesozoic, Rosenkrantz (1960) convincingly showed that lamellibranch, gastropod, and cephalopod assemblages in Denmark were much more like overlying Tertiary than underlying Cretaceous assemblages. Arbitrary assignment of the Danian to the Cretaceous would merely make the rapid transition recognized be within the Mesozoic rather than at the end; this may be what has happened to the near-end Ordovician mass extinction.

The Cretaceous-Tertiary boundary has become continually more tightly defined and recognizable. not less, and particularly so with the introduction of the study of microfossils. The recognition of a global iridium-rich layer (whatever origin is invoked) at the paleontologically defined boundary has led to the layer's use as a marker bed, much as bentonite beds have been used in more local stratigraphies. The new boundary stratotype at El Kef includes the Ir-bearing layer as an important component. It has been possible to precisely correlate some marine and nonmarine records because of the Ir-bearing layer. Some terrestrial disruptions recorded by pollen and other floral attributes took place geologically simultaneously with marine foraminiferal changes. Both ammonite (Ward et al., 1991) and dinosaur (Sheehan et al.. 1991; Sheehan and Fastovsky, 1992) fragments, slightly or not at all reworked, persist to the boundary, and dinosaur footprints have been found less than $37 \mathrm{~cm}$ below the boundary (Pillmore et al., 1994). Rare fragments of reworked dinosaur fragments in floodplains of the lowermost Tertiary are irrelevant.

Some arguments against a rapid turnover are merely permissive rather than demonstrative, for example, that of MacLeod and Keller (1993) that many sections contain a hiatus and that faunal turnover is thus gradual. The conclusion from such evidence is that faunal change might be gradual, not that it is.

The precision and correlation at the Cretaceous-Tertiary boundary are not possible for the Permian-Triassic boundary, for which correlation of marine and nonmarine sequences has proven elusive and equivocal even among marine sequences. That part of the problem may be the incompleteness of the record as a result of regression does not eliminate the reality. Indeed, the placing of the Permian-Triassic boundary has changed with time and author and remains contentious (Erwin, 1993). It is arbitrarily defined on the appearance of various genera, e.g., Oroceras. The oldest definitions were partly lithological. Even the modern differences in placing in fact represent stratigraphic differences corresponding with several million years. The complexity of the Permian-Triassic transition in the record and its underlying causes have been eloquently described and discussed by Erwin (1993. 1994a, b). The transition is indeed marked by the passage beds expected by Murchison and others, with mixed fauna (not reworked) of Permian and of Triassic aspect at continuous sequences. The apparent contrast of the brachiopod-rich faunas of the Permian with the mollusc-rich faunas of the Triassic has been accentuated by the general absence of the Late Permian marine record in the regions with which the early stratigraphers were familiar. There was a massive transition from the Permian to the Triassic, but because the transition took place over several million years, unlike the Cretaceous-Tertiary transition, any boundary is arbitrary. There is no single horizon corresponding with the Ir-bearing layer of the Cretaceous-Tertiary boundary. The extinctions perhaps took place in several pulses (Ward, 1994: Erwin. 1993). Stanley and Yang (1994) have presented evidence that the extinctions took place in two main pulses, one at the end of the Guadalupian and the other at the end of the Tatarian. The ultimate end-Permian pulse is somewhat reduced in intensity from previous suggestions. The resolution available for this final pulse is not yet as distinct as that of the Cretaceous-Tertiary: the total Changxinian (end-Tatarian) is probably about 2 to 3 million ys (Harland et al., 1989), although Stanley and Yang (1994) presume that a shift in $\mathrm{C}$-isotopes over the final 100,000 years relates to the extinctions.

None of the other major boundaries in the stratigraphic record correspond with mass extinctions, except perhaps at the Triassic-Jurassic transition. The boundaries are instead arbitrarily detined. in accordance with the expectations of stratigraphers in the middle part of the last century. Thus the Silurian-Devonian boundary definition has long been subject to debate as to its placing and correlation (Holland, 1965; Earp, 1967). Its eventual definition places it at a horizon at which there was no sudden or dramatic change in life. The Triassic-Jurassic transition and mass extinction, which includes the extinction of several groups of reptiles, amphibians, and ammonites, does not appear to have been abrupt. and the boundary is arbitrarily defined.

The other mass extinctions, such as those of the Upper Ordovician and the Frasnian-Fammenian in the Devonian, do not correspond with major named boundaries. They were recognized as mass extinctions much later than was the CretaceousTertiary boundary. Indeed, the Ordovician itself is a stratigraphic latecomer that is largely arbitrary. with only recently defined boundaries. The Upper Ordovician extinction was completed prior to the end of the Ordovician (Sheehan and Coorough, 1994) and appears to have tracked a glacial epoch. The extinction interval appears to have been 2 to $3 \mathrm{~m}$.y. Iong and to have had several pulses. although Brenchley et al. (1994) have inferred a shorter duration for the glaciation.

The Frasnian-Fammenian extinction has long been recognized as abrupt and global and indeed so abrupt that an impactinduced catastrophic extinction was suggested by McLaren (1970) 1983). Many groups, including trilobites. corals, stromatoporoids, and hrachiopods, were severely affected. However. this boundary has not been historically clearly defined. Harland et al. (1989) placed the boundary at the top of the $P_{(1} l-$ matolepis rrangularis zone, whereas the International Subcommision un Devonian Stratigraphy (in Cowie, et al., 1989) defined the boundary at the base of that zone, corresponding with perhaps $1 \mathrm{~m}$.y. (or more) earlier. This placement closely corresponds with McLaren's (1983) extinction horizon and is marked by a drastic reduction in marine biomass, ecosystem 
diversity, and extinction (McLaren, 1970, 1983; Claeys et al., 1994). It is not known whether this extinction is gradual over several conodont zones or instantaneous at the base of the $P$. $t r i$ angularis zone. Events marking the boundary may have been spread over 2 m.y. (Claeys et al., 1994). No global layer equivalent to the Ir-bearing layer of the Cretaceous-Tertiary boundary is available for correlation, although glassy spherule layers are locally present at different horizons.

The Cretaceous-Tertiary boundary extinction is not just a poor relative of the Permian-Triassic, or any other, mass extinction. It was quite different, was far more abrupt and clear (i.e., the rate was much faster), and affected many more ecological niches, even if the total number of orders. families. or genera that became extinct was smaller than in some other mass extinctions. The Cretaceous-Tertiary transition and the Permian-Trialssic transition are not really comparable in characteristics or in causes: There are mass extinctions and there are mass extinctions. The Cretaceous-Tertiary boundary is an event boundary: that is, something happened. This is in contrast with the previous stratigraphic aim of placing boundaries where abrupt and drastic changes in lithology or fossil content did not occur (McLaren, 1970); that is, no major geological events took place. Such rapid transitions were more or less assumed to indicate an hiatus. This makes the Cretaceous-Tertiary boundary unique in the stratigraphic record as currently defined and understood: a boundary at which something happened. Ultimately other such boundaries might be defined, possibly including the FrasnianFammenian. There is no doubt that the nature of the CretaceousTertiary boundary has been under great scrutiny over the last decade and a half, more so than other boundaries. Nonetheless, this scrutiny cannot be taken to mean that other mass extinctions will necessarily eventually become so contracted in duration; a major reason for the impact hypothesis and the scrutiny of the Cretaceous-Tertiary boundary derives from its very abruptness.

\section{STRAW MEN, COUNTERREVOLUTIONS, AND BURDENS OF PROOF}

Many of those who are at best skeptical and commonly opponents of the impact-extinction hypothesis for the CretaceousTertiary boundary changes have set up straw men and imputed to that hypothesis attributes neither inherent nor generally included in it by impact proponents. Such imputations are that nearly all of the uppermost Maastrichtian extinctions are impact caused (e.g.. Keller et al.. 1993), that virtually everything was instantaneously wiped out worldwide (e.g., Hallam. 1989). and that extraterrestrial catastrophic causes would produce more random extinction than terrestrial gradualistic causes (e.g.. MacLeod, 1994). Some workers have demanded exact burdens of proof of "impactors" but have not demanded such proofs of themselves; for instance. "impactors" alone are criticized for not explaining the survival of crocodiles and turtles (although some impact scenarios have suggested survival mechanisms with detritus-hased food chains).

Proponents of terrestrial causes, such as seat-level changes. have usually failed to portray the mechanisms much beyond speculation, and such mechanisms are currently little advanced and are even less consistent with current constraints than they were prior to the publication of Alvarez et al. (1980). Although many mechanisms, such as habitat fragmentation as a result of sea-level changes, might explain particular extinctions, they cannot yet be held capable of causing global extinctions over many different types of environment. Similar criticism can be made of those invoking a volcanic or mantle hypothesis (e.g.. McCartney et al., 1990; Officer et al., 1992). Obviously there is a requirement to understand what is inherent in or predictable with an impact-caused extinction or any other type of extinction hypothesis.

\section{Reality of a boundary impact event}

The presence of an iridium-rich layer, shocked quartz, and the identification of perhaps the largest Phanerozoic impact crater-with a stratigraphic and radiometric age indistinguishable from that of the boundary elsewhere-have convinced most workers that there was a boundary impact event. There remain considerable differences in opinion of the significance, if any, of that event for extinctions. An important historical point is that the abruptness of extinctions led to the analysis for iridium at a particular horizon as a potential determinant of sedimentation rate. That measurement led to the inference of an impact at the time represented by that horizon. This in turn led to the hypothesis that the impact was responsible for the extinctions, from the inference that this coincidence was causal (and extinctions obviously cannot be held responsible for impacts). The impact hypothesis is not in itself dependent on a specific mechanism(s), although such mechanisms were reasonably suggested, including rapid and dramatic climate changes from dust clouds and other atmospheric effects. Many counterrevolutionary papers (i.e., those that deny an impact cause) over the last decade, however, give the impression that it is those who invoke an impact who have required a particular paleontological significance. for instance that impact proponents claim abrupt extinction. Yet it was never the case that an impact was inferred and that then there was a search for associated extinctions. It is an ironic reversal that some paleontologists chose to reduce the significance of the boundary after the impact was inferred. Rather than evaluate the record in the light of an impact, they chose to construct inappropriate straw men.

\section{Impact and extinction timing patterns}

Some paleontologists have made an effort to show that (stepped) extinctions were taking place in the Late Cretaceous up to the boundary; they follow with the specious conclusion that the impact had no significant effeci (c.g.. Keller. 1989: Keller et al., 1993). Exactly what "stepped extinction" means has not been defined, but it seems to imply some relationship among the steps rather than just some random, preboundary 
extinctions. Clearly some explanation is required for why planktonic foraminifera (for instance) should go extinct in steps in some clear order. Identification of relevant "stepped extinction" requires exceptionally fine stratigraphic resolution and needs to take full account of the Signor-Lipps effect. The steps also need to be shown to be globally correlative. The impact hypothesis, however, in no way requires that all or eyen most of the upper Maastrichtian extinctions resulted from the impact, and unless the "stepped extinctions" are causally related to each other they have no bearing on the reality of impact extinctions.

The impact hypothesis does demand that those extinctions that essentially define the change from Mesozoic to Cenozoic took place fairly rapidly as a result of (and therefore not before) the impact. This demand is fultilled in the drastic microfaunal changes, the floral changes, and the extinction of ammonites. belemnites, dinosaurs. and probably marine reptiles that took place within analytical stratigraphic uncertainty of the boundary (e.g., Coccioni and Galeotti, 1994: Sheehan et al.. 1991: Sheehan and Fastovsky, 1992; Ward et al. 1991). That inoceramids did not survive as far as the boundary, or that some foraminifera went extinct earlier. is (or may be) correct but does not deny the later catastrophic extinction. There were obviously continuing extinctions within the upper Cretaceous. Some of those extinctions historically linked with the CretaceousTertiary boundary, including inoceramids, can no longer be used to define it.

The persistence of genera, or even species, through the boundary, even if they went extinct shortly after, does not deny the reality of impact-caused exinctions either. Even though there were almost certainly considerable geologically immediate effects of an impact, longer-term effects seem unavoidable. Thus Hallam's (1989) statement that exact contemporaneity of extinctions is required by the impact hypothesis is at best misleading. There is an unnecessary polarization of concepts: that either extinctions are not related to an impact or that all extinctions are related to an impact. In reality, some extinctions could precede and be unrelated to an impact, others could be an almost direct or near-term result of impact effects such as atmospheric heating or darkness, and others could be slower responses, perhaps over a few years to many tens of thousiands of years, to a dramatically changed environment that is still in biotic instability. Keller (1989) has suggested that an extended period of extinctions that she infers over the CretaceousTertiary boundary is incompatible with the impact hypothesis for extinctions. Keller et al. (1993) similarly state that impact proponents have long argued that at large bolide impact caused the extinction of nearly the entire Cretacesus biota and then ure their conclusion that there were gradual extinctions at high latitudes to deny the general significance of an impact. Whether or not there was an extended period of extinctions, such a test imputes to the impact hypothesis an attribute that it does not have and that impact proponents have not (usually) required of it. Catastrophic collapse does not necessarily mean instantatneous and total collapre.

\section{Impact and extinction selectivity patterns}

Those skeptical of impact-related extinction have lurned to demonstrating the case for selective extinctions, such as particular groups of animals or latitude-dependent effects, and concluding that these are more compatible with a nonimpact scenario than with an impact one (e.g.. Keller et al., 1993; MacLeod and Keller. 1993; Archibald, 1994). Such a conclusion depends upon a knowledge of extinction mechanisms in both gradual and abrupt situations, the very things researchers are currently attempting to understand. Ecosystems today are complex and incompletely understood, and that of the terminal Cretaceous is far more removed from observation and analysis Perhaps an analog would be to investigate the remains of a ruined house of cards and attempt to determine which cards were first removed and how. Thus Archibald's ( 1994 ) claim thall the pattern of extinction of vertebrates is incompatible with an impact hypothesis relies on a claim of understanding of the relevant ecosystems that is currently not possible. It ultimately may have merit, once the relevant impact environmental effects are better known. It is presently inconsistent and inappropriatc to claim that impact is incompatible with crocodilian survival yet claim that sharks would be decimated by sea-level regression and habitat fragmentation (Archibald, 1994, Table 1). Similarly, the claim by Clemens and Nelms (1993) that an impact cannot explain the extinction of some high-latitude Dinosauria has no firm basis; it is certainly not a crucial experiment. A few years ago few researchers would have thought that dinosaurs could have lived at such high latitudes at all; their discovery emphasizes how much we have to learn about how various dinosaur groups lived.

To suggest that gradual climatic changes or sea-level changes caused abrupt extinctions is to divorce the direct mechanism from the indirect one, with the same problems of interpretation and association as the impact scenario. Few totat killing mechanisms (or altematively reproduction-inhibiting mechanisms) have yet been certainly established for any hypothesis. Many suggested mechanisms are not demonstrated hut highly speculative, and even such dramatic climate changes as the cooling of the last Ice Ages did not result in significant. and certainly not a mass, extinction. Decimation of the large vertebrate species hald a human. not climatic, cause. Keller et al. (1993) clamed that changes created by an impact at the end of the Cretaceous would not have affected tropical more than high. latitude environments. This is an unfounded claim. not only because that impact took place in the tropics. It is certainly in undemonstrated claim.

\section{CONCIUSIONS: THE UNIQUE BOUNDARY AT THE MESOZOIC-CENOZOIC TRANSITION}

The abruptness and importance of the Cretaceous-Tertiary boundary have been recognized from the birth of stratigraphy. and the fundamental change from Mesozoic to Cenoroic has 
come to be continually more tightly constrained over 180 years. The significance of the boundary is not merely a product of dinosaur-fascination and the fantasies of those who postulate that an impact took place at the end of the Cretaceous Period. Rather, the significance of the boundary is a product of its unique sharpness and the important faunal changes. The Cretaceous-Tertiary boundary is a much more abrupt boundary than that of the Paleozoic-Mesozoic or of any other mass extinction or stratigraphic boundary as currently described. The Cretaceous-Tertiary boundary is unique in being essentially nonarbitrary and generally easily, precisely, and indisputably identifiable in at least marine sections. It is also unique in being a definite event boundary.

An impact hypothesis provides the most consistent and coherent understanding of the origin of the Cretaceous-Tertiary boundary, relating features as distinct as planktonic foraminiferal extinctions in Denmark, dinosaur extinction in Montana, tremendous loss of productivity at the boundary, iridium-bearing layers in the Raton Basin, shocked quart $z$ in New Zealand. rapidly deposited spherule beds in a deep-water sequence in northeast Mexico, and a large buried crater in the Yucatan. Terrestrial-origin hypotheses such as sea-level changes as favored by Newell $(1962,1963)$ or volcanic activity (McCartney et al., 1990; Officer et al., 1992; Courtillot, 1990) do not have such unifying attributes without claiming coincidences and even when claiming speculations (such as shocked quartz and iridium to be from volcanic sources) as truths. Those who are skeptical of the impact hypothesis should not demand more of it than is inherent in it; too many straw men have led to confusion on what are the relevant issues and tests.

\section{ACKNOWLEDGMENTS}

This chapter is LPI Contribution 862. Reviews by Peter Sheehan, David Archibald, and an anonymous reviewer and comments by David Fastovsky led to considerable improvements (I hope) of the chapter. None of them necessarily agrees with any individual or combined polemics of this contribution. The Lunar and Planetary Institute is operated by the Universities Space Research Association under contract NASW-4066 with the National Aeronautics and Space Administration.

\section{REFERENCES CITED}


cause for the Crelacenus-Tertiary extinction: Science. 1. $20 \%$. p. $1095-1108$.

Arthibald. J. D.. 1994. Testing KT extinction hypotheses using the vertebrate fossil record, in New develupments regarding the KT event and other catastrophes in Earth history: Houston. Texas. Lunar and Planelary Institute Contribution 825, p. 6-7

Bramlette. M. N. 196.5. Massive extinctions in biotat at the end uf Mesomic ime: Science. v. 148. p. 1696-1609

Brenchley, P. J., Marshall, J D. Carden. (3. A. E. Robertson. D). B. R. L.ong, D. (j. F.. Meidla, T., Hints. I... and Andetsont. T. F. 1994. Bathynetric and isotopic evidence for a short-lived Late Ordovician glaciation in it greenhouse period: Geology, v. 22, p. 295-298.

Claeys. P., Kyte. F. T., and Casier, J.-G., 1994, Frasnian-Fammenian boundary: Mass extinctions, anoxic oceans, microtektite layers. but not much iridium? in New developments regarding the KT event and other catastrophes in Earth history: Houston. Texas, Lunar and Planetary Institute Contribution 825, p. 22-24.

Clemens, W. A., and Nelms, L. G., 1993, Paleoecological implications of Alaskan terrestrial vertebrate fauna in latest Cretaceous time at high paleolatitudes: Geology, v. 21, p. 503-.506.

Coccioni. R.. and Galeotti. S., 1994, K-T boundary extinction: Geologically instantaneous or gradual event? Fvidence from deep-iea benthic foraminitera: Geology, * 22, p. 779-782

Colbert. E. H. 1965. The age of reptiles: New York. W. W. Norton. $228 \mathrm{p}$.

Courtillot. V.. 1990. A voleatnic eruption: Scientific American. v. 26.3. p. 8.5-92.

Conke. J. W. Ziegler W., and Remane. J. 1989. Stratigraphic Commission accelerates progress. 1984 to 1989: Episodes, 1. 12. p. 79-83

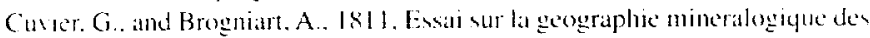
envirom de Paris (Stratigraphy of the Paris Basing): Memoires de la Classe des Sciences Mathematiques et Physiques de l'Institut Imperial de Frame 1810 . p. 1-27s.

Darwin. C.. Is.ie. The origin of species ( I st ed.): Londom. John Murray. 490 p). d'Halloy, J. J. O.. 1822. The systematic classification of geologic formations: Annales des Mines. v. 7. p. 353-376.

Earp. J. R., 1967. The Siluro-1)evonian boundary: Geological Magazine. S. 104. p. $401-403$.

Erwin. D. H. 1993. The great Paleozoic crisis: Life and death in the Permian: New York. Columbia University Press, 327 p.

Erwin. D. H.. 1994a. The Permo-Triassic extinction: Nature, v. 3647. p. $231-236$.

Erwin. D. H.. 1994b. The end-Permian mass extinction, A complex, multicausal extinction. in New developments regarding the KT event and other calastrophes in Earth history: Houston. Texas, lunar and Plane. tary Institute Contribution 825, p. 33-34.

Hallam, A. 1989. Great geological controversies: New York. Oxford Science Publications, Oxtord University Press, 244 p.

Harland. W. B.. Armstrong. R. L., Cox, A., Craig. L. E.. Smith, A. G.. and Smith. D. G.. 1989. A geologic time scale 1989: Cambridge, Cambridge Liniversity Press. $26.3 \mathrm{p}$.

Hay. W. M.. 1960. The Cretaceous-Tertiary boundary in the Tampico embayment. Mexico: Proceedings, International Geological Congress. 2lst. Copenhagen. pt. 5. p. 70-77.

Hollond. C. H.. 1965. The Siluro-Devonian boundary: Cieological Magazine. v. 102. p. 213-221.

Keller. G.. 1989. Extended period of extinctions across the Cretaceous/Tertiary houndars in planktonic foraminifera of cominental shelf sections: Implications for impact and volcanism theories: Geological Society of America Bullesin. v. 101 , p. $1408-1419$.

Keller. G.. Barrera. E.. Schmile, B.. and Mattston, F.. 1993. Gradual mat extinction. species survivorship, and long-term enviromental thatnge aross the Crelacenus-Fentaly houndary in high lationdes: Geological Socien of America Bulletion, v. 105, p. 979-997.

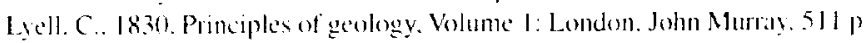

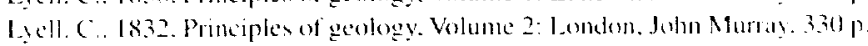


and appendices


spectes survising a mass extinetion. in New developments regardinge the KT 2 ent and other caltastrophes in Earth history: Houston. Texas. L.unat and Plankelary Im

Makead. N. and heller: G. 1993. Hiatus distributions and mass extinctions at the Cetaceous/ Tertiary houndary: Ceology, v. 19. p. f97-501

M.Cantey. K.. Hutliman. A. R., and Tredoux. M. 1990. A paradigm ho condegeneus atusation of mass extinctions, in Shatpton. V. L... and 
Ward. P. D., eds., Global caltastrophen in Larth history: an interdisciplinary conference on impacts, volcanism, and mass mortality: Geobogical Society of America Special Paper 247. p. 12.5-1.38.

Malaren. D. J. 1970. Time, life, and boundaries: Journal of Paleontology, v. 44 , p. $801-815$.

McLaren, D. J., 1983. Bolides and biostratigraphy: Geological Society of America Bulletin, v. 94, p. 313-324.

Murchison, R. 1., De Verneuil. E., and von Keyserling. A.. 1845. The geology of Russia in Europe and the Ural Mountains: London, John Murray.

Newell. N. D., 1962. Paleontological gaps and geochronology: Journal of Paleontology, x. 36, p. 592-610.

Newell. N. D. 1963. Crises in the history of life: Scientific American. v. 208. p. $77-93$.

Officer. C. B., Drake. C. I.. Pindell. J. L.. and Meyerhoff. A. A.. 1992. Cretaceous-Tertiary events and the Caribbean caper: GSA Today, v. 2. p. $69-70.73-75$

Phillips, J.. 1841, Palcozoic fossik of Commall. Dewon, and West Somerset: Great Britain Geologeal Memotr. 100 p.

Phillips. J. 1860. Lile on Earth. It origin and wecession: Cambridge. Macinillan

Pillmore. C. L.. Lockley. M. G.. Flenuing, R. 1. and Johnuon, K. R. 1994. Footprints in the rocks-New evidence from the Raton Basin that dinosaurs tourished on land until the terminal Cretaceous impact event, in New developments regarding the KT event and other catastrophes in Earth history: Houston. Texas, Lunar and Planetary Institute Contribution 825. p. $89-90$

Rainwater, F. H., 1960 . Paleocene of the Gulf Coastal Plain of the United States of America: Procecdings. Imernational Geological Congress. 2lst. Copenhagen. pt. 5, p. 97-116.

Raup. D., 1991. Extinction: Bad genes or bad luck'? New' York. W.W. Norton. $210 \mathrm{p}$.

Rosenkrantz, A.. 1960. Danian mollusca from Denmark: Proceedings. Interna- tional (jeolugical Congress, 2Ist, Copenhagen, pt. 5, p. 193-198.

Russell. D A.. 1979. The Cretaceous-Tertiary boundary problem: Episodes. v. 1979. . . 21-24.

Ryder, G., 1994, KT boundary: Historical context, counter-revolutions, and strawmen, in New developments regarding the KT event and other catastrophes in Earth history: Houston. Texas, Lunar and Planetary Institute Contribution 825, p. 101-103.

Sheehan. P. M.. and Corrough. P. J.. 1994, Were all extinction events caused by impacts? in New developments regarding the KT event and other catastrophes in Earth history: Houston, Texas, Lunar and Planetary Institute Contribution 825. p. 110-112.

Sheehan. P. M.. and Fastovsky, D. E., 1992, Major extinctions of land-dwelling rertebrates at the Cretaceous-Tertiary boundary, eastern Montana: Geoloyy. 2. 20. p. $556-560$.

Sheehan. P. M.. Fastovsky, D. E.. Hoffman, R.G., Berghaus, C. B.. and Gabriel D. 1. 1991. Sudden extinction of the dinosaurs: Iatest Cretaceous. Upper Great Plains. U.S.A.: Science. v. 254, p. 835-839.

Stanles. S. M. 1987 . Extinction: New York. Scientific American 1.ibrary. Frec. mala. $2+3 p$.

Stanley. S. M., and Yung, X. 1994. A double mass extinction at the end of the Paleoroic era: Science, v. 266. p. 1340-1,344.

Ward. P. D. 1944. Dissecting the KT extinction: Components and comparisons with the Permo-Triassic and "modern" mass extinctions, in New developments regarding the KT event and other catastrophes in Earth history: Houston, Texas, Lunar and Planetary Institute Contribution 825, p. 127.

Ward, P. D.. Kennedy. W. J., MacLeod. K. G., and Mount, J. F., 1991. Ammonite and inoceramid bivalve extinction patterns in Cretaceous/Tertary boundary sections of the Biscay region (southwestern France, northern Spain): Geology, v. 19. p. $1181-1184$.

Mandiscripl Acrepted by the Society September 14, 1995 